\title{
Fatores críticos de sucesso em projetos colaborativos na indústria de máquinas agrícolas
}

\author{
Euclides Reame Junior ${ }^{\mathrm{a} *}$, Daniel Capaldo Amaral ${ }^{\mathrm{b}}$ \\ a*reamejunior1959@uol.com.br, FATEC, Brasil \\ bamaral@sc.usp.br, EESC-USP, Brasil
}

\begin{abstract}
Resumo
Os projetos colaborativos de novos produtos são fundamentais para que empresas aumentem o grau de inovação em seus produtos. Bons resultados dependem da identificação de fatores críticos de sucesso (FCS) e não há tais estudos na Indústria de Máquinas Agrícolas (IMA). 0 artigo verifica se os FCS identificados na literatura poderiam ser utilizados em levantamentos do setor e se há outros a considerar. Apresenta revisão bibliográfica e levantamento em empresa com elevado nível de maturidade em PDP frente às empresas da IMA. Empregou-se o método de estudo de caso único, do tipo incorporado. A unidade de análise são projetos do tipo colaborativo e de sucesso: dois deles no total. Identificam-se fatores que podem não ser críticos, apesar de apontados pela literatura; indica-se a existência de novos FCS e reforça-se a importância dos fatores ligados à garantia de igualdade e fatores universais de sucesso. Palavras-chave

Projetos colaborativos. Máquinas agrícolas. Fatores críticos de sucesso.
\end{abstract}

\section{Introdução}

Colaborar com clientes, fornecedores, institutos de pesquisa e universidades para desenvolver novos produtos é uma das principais alternativas para se enfrentar o desafio da inovação tecnológica. Esse desafio depende de investimentos significativos, o que está levando a uma mudança na estrutura de pesquisa e desenvolvimento presente nas empresas.

Ao invés de manter estruturas grandes e autossuficientes, elas buscam realizar parcerias com os agentes externos, transferindo parte do esforço para as ações conjuntas. Essa forma de atuação é destacada por Huston e Sakkab (2006), que descrevem o caso da empresa Procter e Gamble. Segundo os autores, aproximadamente $45 \%$ da linha de produtos da empresa são desenvolvidos em colaborações com outros agentes ao redor do mundo. Essa estratégia utilizada pela Procter e Gamble é reconhecida como Inovação aberta (Open Innovation), conceito desenvolvido pelos autores Chesbrough (2003) e Chesbrough e Schwarts (2007).

No caso da IMA, os maiores fabricantes mundiais, a partir dos anos de 1990, estão diminuindo a participação das tecnologias tradicionais utilizadas nos produtos do setor (como materiais, pneumática e hidráulica) em função de uma participação da microeletrônica (softwares, sensoriamento e comunicação de dados), originando-se o conceito de "agricultura de precisão".

Essas novas tecnologias possibilitaram uma nova geração de máquinas e implementos capazes de tratar de maneira específica os insumos, planta ou animal (no caso de máquinas e implementos para criação animal). Nicoletta (2008) afirma que especificamente o mercado de colheitadeiras e tratores para cana no Brasil cresceu nos últimos cinco ou seis anos e atingiu um patamar quase estável em 2008, com previsões de um avanço de 2009 a 2012, crescendo de 10\% a 15\% a partir de 2009. Para que a IMA brasileira continue atuando dessa forma, será fundamental a incorporação das novas tecnologias, atualizando-se frente ao movimento da agricultura de precisão. E uma das estratégias é o avanço em pesquisas e no desenvolvimento de novos produtos por meio da colaboração com outras organizações (clientes, fornecedores, universidades, institutos de pesquisa). 
Este artigo descreve os resultados de um estudo de caso realizado em uma empresa do setor de máquinas e implementos agrícolas localizada no interior do estado de São Paulo. 0 objetivo foi ilustrar os desafios enfrentados por uma empresa com elevada maturidade em DP frente a outras do setor e verificar os modelos teóricos sobre fatores críticos de sucesso em projetos colaborativos, aprimorando-os para a construção de instrumentos para levantamentos abrangentes. Apresenta-se uma breve revisão bibliográfica sobre a colaboração em desenvolvimento de produtos, suas vantagens e dificuldades, e sobre FCS. Em seguida, apresenta-se o método da pesquisa, os resultados obtidos e as análises. Por fim, discussões e conclusões gerais.

\section{Revisão bibliográfica}

\subsection{A inovação e a colaboração na indústria de máquinas agrícolas}

A indústria de máquinas agrícolas (IMA) é parte da indústria de bens de capital (AVELLAR, 2008) e é formada pelo conjunto de empresas que produzem máquinas e equipamentos para a produção agrícola, denominados de máquinas e implementos.

Convém esclarecer a diferença entre "máquinas" e "implementos". Para Gadanha Junior et al. (1991), as máquinas são conjuntos de componentes com movimentos suficientes para transmitir o efeito de forças ou energia; são "motoras" quando transformam o efeito e "movidas" quando transmitem o efeito. Os implementos são conjuntos de componentes que não transformam energia.

Mialhe (1974, p. 16) conceitua de maneira mais apropriada, definindo máquinas e implementos da forma descrita a seguir:

Máquina é o conjunto de órgãos, forçados em seus movimentos por obstáculos fixos e de resistência suficiente para transmitir o efeito de forças e transformar energias. Tanto o motor do trator quanto o arado são considerados máquinas, uma vez que, no primeiro, há transformação de energia e, no segundo, apenas transmissão do efeito de forças.

0 implemento é:

0 conjunto forçado de órgãos que não apresentam movimentos relativos nem têm capacidade para transmitir força, sendo seu único movimento o de deslocamento, normalmente imprimido por uma máquina tratora. (MIALHE, 1974, p. 16).

0 surgimento desse setor no Brasil se relaciona com a imigração europeia nas décadas de 1930 e 1940. Imigrantes, vindos para trabalhar na agricultura e com conhecimentos de mecânica e metalurgia, começaram a produzir artesanalmente as primeiras máquinas e implementos (PASQUAL; PEDROZO, 2007).

0 desempenho da IMA brasileira foi irregular, alternando períodos de evolução e crises, acompanhando oscilações da própria atividade agrícola. A produtividade do setor também sempre foi considerada baixa. Mas esse cenário começou a mudar ao final da década de 1990, quando as empresas passaram a integrar novas tecnologias em produtos e processos (ROMANO, 2003).

Em 1999, com a criação do Programa de Modernização da Frota Agrícola (Moderfrota), a produtividade do setor apresentou crescimento entre 2000 até 2004, porém fatores como o câmbio, aumento dos insumos e a seca prejudicaram o desempenho em 2005 (ASSOCIAÇÃO... 2006).

Em 2007, o segmento de máquinas e implementos agrícolas apresentou recuperação principalmente em função da cultura de grãos e dos negócios relacionados às usinas produtoras dos derivados da cana-de-açúcar (ASSOCIAÇÃO... 2007).

No mesmo segmento, o aporte tecnológico trouxe competitividade para as máquinas semeadoras, adubadoras, pulverizadoras, tratores e colheitadeiras (SAVANACHI, 2007). Um dos principais conceitos nessa direção é a chamada agricultura de precisão.

De acordo com Clarck e McGuckin (1996), a agricultura de precisão envolve sistemas automáticos compostos por: microcontroladores, sensores e atuadores acoplados ao equipamento agrícola e interligados ao Sistema de Posicionamento Global (SPG). Molin, citado por Cerri (2005), enfatiza que a agricultura de precisão dispõe um elenco de tecnologias e procedimentos para que as lavouras e os sistemas de produção sejam otimizados.

Para Martini et al. (2006), a agricultura de precisão permite gerar mapas das áreas produtivas com informações valiosas para um melhor gerenciamento metro a metro do talhão, visando redução de custos.

Outros recursos desenvolvidos são os dispositivos que possibilitam a orientação por satélites, sistemas de piloto automático e a eletrônica embarcada (SAVANACHI, 2007). Tratores conduzem o plantio por linhas exatas, com mais rapidez e também com mínima margem de erro, dando origem à agricultura de precisão (MARTINEZ, 2007). Os sistemas de piloto automático garantem o paralelismo de atividades na lavoura, principalmente nas atividades de sulcagem e colheita da cana (SAVANACHI, 2007).

Capelli (2008) argumenta que as vantagens estabelecidas pela agricultura de precisão são: possibilitar o melhor conhecimento do campo de produção e, consequentemente, melhores decisões sobre plantio e uso dos recursos; oferecer uniformidade e produtividade pela correção dos fatores que contribuem para variabilidade; e contribuir com a 
preservação do meio ambiente, racionalizando o uso de insumos.

Além do aumento da eficiência, a inovação tecnológica das máquinas agrícolas brasileiras também acompanha a tendência de substituir os combustíveis fósseis por biocombustíveis, com o objetivo de reduzir as emissões de gases poluentes (TORRICO, 2007).

0 Brasil é reconhecido pela comunidade internacional como um dos líderes mundiais no setor agrícola. As fazendas em setores como açúcar e álcool, soja e criação de gado bovino empregam as melhores tecnologias e exigirão certamente que os fabricantes nacionais disponham de produtos para atendê-los. A inovação tecnológica na IMA nacional, em direção à agricultura de precisão, será fundamental para a manutenção dessa indústria. Uma das estratégias importantes está nas colaborações com universidades, institutos de pesquisa, empresas de base tecnológica e fornecedores. A seguir, discute-se esse tipo de projeto.

\subsection{Vantagens em projetos colaborativos de desenvolvimento de produtos}

A colaboração é uma das práticas fundamentais para a inovação, conforme demonstrado recentemente por Blindenbach-Driessen e Van den Ende (2010). Para Badin (2005), a colaboração no desenvolvimento de produtos (DP) possibilita desempenho econômico e tecnológico melhor, além de ganhos de conhecimentos. Já para Dong et al. (2005), a colaboração permite a realização de trabalhos simultâneos em tarefas independentes. Parung e Bititci (2006) entendem que a colaboração proporciona vantagens competitivas de mercado.

Na opinião de Sivadas e Dwyer (2000) e Chesbrough (2003), as vantagens dos projetos feitos em colaboração começam a partir do momento em que há um fluxo contínuo de informações entre os parceiros para garantir uma integração e flexibilidade melhores. Essa linha de pensamento também é confirmada por Kleinsmann e Valkenburg (2005), que afirmam que uma colaboração é solidificada por uma comunicação efetiva em todas as fases que envolvam o projeto. $\mathrm{Na}$ visão de Hagedoorn (1993), Griffin (1997), Barnes, Pashby e Gibbons (2002), Lam e Chin (2004) e Knudsen (2007), esses projetos podem apresentar as seguintes vantagens:

- Redução de custos, de riscos e falhas;

- Acesso a novos conhecimentos e competências;

- Novos recursos para novas tecnologias;
- Compartilhamento de informações, desde que auxiliado por técnicas e ferramentas de gerenciamento de projetos; e

- Atendimento mais rápido das demandas de mercado.

Conforme Von Stamm (2004), a colaboração entre agentes para desenvolver novos produtos pode proporcionar às empresas melhorias em seus processos internos e também um novo corpo de conhecimento.

No entendimento de Claro e Oliveira Claro (2004), essas vantagens serão alcançadas somente se todas as questões relacionadas aos projetos elaborados em colaboração para desenvolver os produtos forem bem gerenciadas, com os objetivos e prazos alinhados, transparência e comprometimento das equipes e capacidade para administrar riscos.

\subsection{Dificuldades em projetos colaborativos de desenvolvimento de produtos}

Há vários trabalhos que descrevem os fatores que podem dificultar a consecução desses projetos. Os principais são de Hamel, Doz e Prahalad (1989), Dodgson (1992), Grudin (1994), Domazet et al. (2000), Barnes, Pashby e Gibbons (2002), Lam, Chin e Pun (2007) e Toledo et al. (2008a, b). Sintetizando os principais problemas apresentados, obtém-se a lista descrita a seguir.

- A quebra de sigilo em informações, experiências ou conhecimentos que não estejam no âmbito da colaboração é um risco, pois possibilita a um dos agentes não somente adquirir as competências no desenvolvimento de produtos, mas ter acesso aos demais negócios da empresa parceira;

- 0 gerenciamento insatisfatório ou falta de liderança, que podem facilitar a perda de controle do processo, a desmotivação e o desentendimento entre as equipes;

- A dispersão geográfica e também a utilização de diferentes recursos computacionais comprometem o processo;

- A existência de agendas ocultas;

- Os níveis diferenciados de conhecimentos em relação aos assuntos técnicos e das especificações do produto;

- Os desacordos e conflitos que poderão surgir entre as partes em virtude das diferentes práticas utilizadas nos procedimentos que envolvam o desenvolvimento do produto; e

- As diferenças culturais entre as partes, principalmente relacionadas ao idioma.

Além de problemas relacionados ao idioma, Schneider (1995) apresenta outras diferenças culturais que podem pôr em risco todo o projeto.

- Estilos de atuação. Cada cultura tem seu próprio estilo (paciência, flexibilidade, ponderação). Eles 
podem variar e prejudicar o projeto quando não sincronizados;

- Experiência profissional. Há culturas em que pessoas com mais idade e experiência profissional são consideradas mais influentes e com o perfil indicado para assumir maiores responsabilidades ou a gerência dos projetos. Em outras, os níveis de maior responsabilidade de um projeto são delegados às pessoas em idade não tão avançada, por se considerar que possuem mais disposição e dinamismo e são mais proativos; $\mathrm{e}$

- Aproveitamento do tempo. Algumas culturas fazem um melhor uso do tempo, dividindo as tarefas e atividades. Outras culturas o "pulverizam”, ou seja, procuram realizar várias tarefas e atividades conjuntamente, não estabelecendo prioridades, prejudicando assim os resultados globais de um projeto.

De acordo com Romano (2003), para que os projetos colaborativos possam atingir as metas e os objetivos propostos, é necessário estabelecer um conjunto de atividades chaves ou fatores críticos de sucesso (FCS). Barbalho et al. (2009) apresentam como um fator importante para colaborações que envolvam produtos com novas tecnologias o envolvimento de um escritório de projetos.

\subsection{Fatores críticos de sucesso em projetos colaborativos de desenvolvimento de produtos}

Os FCS formam um conjunto das atividades-chave que devem existir em uma colaboração para que os resultados do projeto sejam favoráveis (ROCKART, 1979). Orientando-se pelas considerações feitas pelo autor, foram pesquisados na revisão bibliográfica cinco trabalhos que identificavam FCS em projetos colaborativos de desenvolvimento de produto. Esses trabalhos são os de Barczak e Wilemon (2001), Hyväri (2006), Heinz et al. (2006), Barnes, Pashby e Gibbons (2006) e Albertin e Amaral (2010).

0 Quadro 1 sintetiza os FCS citados nos referidos trabalhos. Os campos em destaque representam os FCS citados em cada artigo.

0 FCS gerenciamento de riscos não foi descrito em nenhum dos trabalhos pesquisados mas foi considerado como tal nesta pesquisa. 0 motivo foram trabalhos recentes apontando-o como fundamental para projetos colaborativos. Van Wyk, Bowen e Akintoye (2008) o afirmam a partir de um estudo de caso em empresa de grande porte localizada na África do Sul. Segundo os autores, a direção da empresa considera o gerenciamento de riscos em projetos um assunto afeto ao planejamento estratégico da empresa. Todas as unidades de negócios e subsidiárias da empresa possuíam comitês para desenvolver estratégias de gerenciamento de riscos em projetos. Barbalho et al. (2009) citam que a diminuição de riscos nos projeto foi um dos aspectos fundamentais da implementação de PMO em empresa que desenvolve projetos de novas tecnologias. Há também vários trabalhos propondo soluções para o gerenciamento de riscos. Por exemplo, Kayis e Irmas (2007) desenvolveram um software para realizar com eficácia todo o gerenciamento de riscos, integrando de forma sistemática o desenvolvimento de produtos e processos.

\section{Metodologia da pesquisa}

A primeira constatação é que os casos de projetos de desenvolvimento envolvendo inovações são raros nessa indústria. Similar ao resultado de Simões (2007) e Toledo e Simões (2010), das empresas contatadas poucas se enquadravam nas condições para a pesquisa: projetos colaborativos e de inovação tecnológica. Quando o fizeram, havia barreiras de confidencialidade e tempo dos profissionais. Tornou-se evidente que seria difícil reunir um conjunto grande de casos em empresas distintas. Optou-se, então, por estudar apenas uma empresa, em profundidade, mas que apresentasse um alto nível de maturidade em PDP no setor e projetos colaborativos com diferentes fontes: clientes e universidades. Assim, procurar-se-ia uma empresa com maior probabilidade de ter as práticas mais avançadas para verificar a lista de FCS.

0 estudo pode ser considerado como caso único e incorporado. Conforme Yin (2005, p. 20), esse tipo de estudo de caso permite uma investigação para se preservar as características holísticas significativas dos acontecimentos da vida real. 0 projeto de caso único é indicado, segundo o autor, sob certas condições: quando o caso permite um teste crucial de uma teoria existente; quando há circunstância rara ou exclusiva; quando um caso é típico ou representativo; ou quando o caso serve a um propósito revelador ou longitudinal. Nesta pesquisa, entende-se que o tipo de colaboração é raro.

Ainda segundo o autor, a definição da unidade de análise é uma etapa fundamental para se projetar e conduzir um caso único. A unidade de análise é cada projeto colaborativo de sucesso, em um total de dois, encontrados no caso identificado. Os critérios para a escolha dos projetos são: a) ser considerado de sucesso, isto é, que, na opinião do entrevistado, tenha obtido os resultados esperados e que tenha sido significativo para a empresa; b) possuir um grau de inovação e complexidade.

Para entender todo o processo da colaboração desses projetos foi aplicado um questionário-roteiro, 
Quadro 1. Síntese dos fatores críticos de sucesso (elaborada pelo autor).

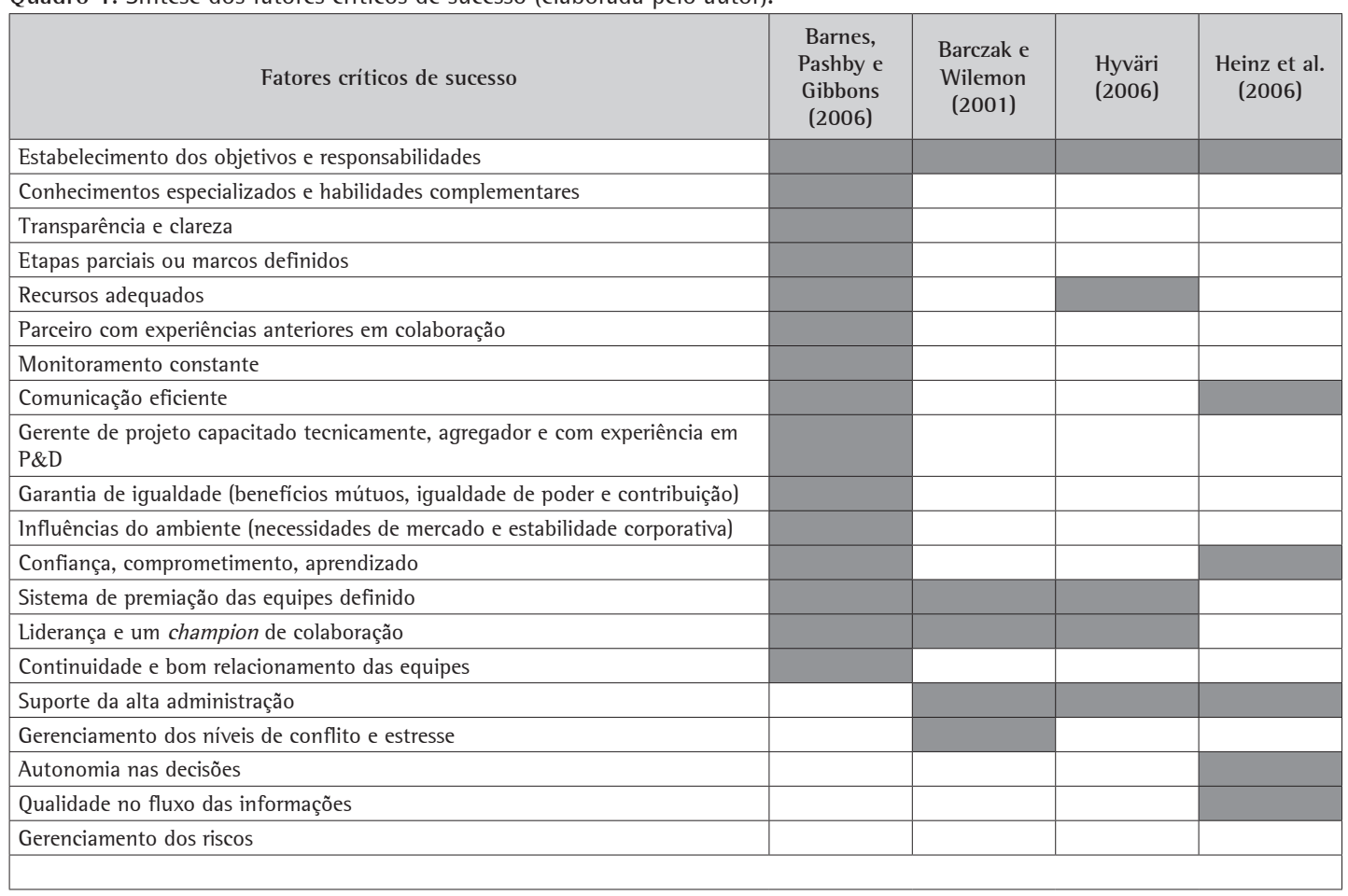

respondido pelo responsável pela área de engenharia de desenvolvimento de produtos da empresa. Foram oito horas de entrevistas e consultas à documentação dos dois projetos. As entrevistas foram realizadas na empresa e o pesquisador pôde verificar a documentação e os produtos que foram desenvolvidos. Por sigilo profissional e acadêmico, a empresa será referenciada como "a empresa estudada".

0 roteiro de pesquisa foi estruturado em quatro partes. A primeira e a segunda versavam sobre o processo de desenvolvimento de produtos da empresa. As outras duas se referiam aos projetos em si e foram aplicadas separadamente para cada projeto estudado (1 e 2).

A primeira, chamada "caracterização da empresa”, avaliou as dimensões necessárias para verificar se a empresa apresenta nível de maturidade em desenvolvimento elevado, segundo a indústria. Empregaram-se as dimensões identificadas no levantamento de Simões (2007) e Toledo e Simões (2010) sobre o perfil da gestão de desenvolvimento de produtos das empresas da indústria de máquinas agrícolas, dados apresentados na seção 4.2. A segunda parte, denominada "colaboração na empresa", serviu para caracterizar o histórico da empresa quanto à prática de parcerias. Tempo de manutenção de parcerias, motivações para colaborar, critérios utilizados para a escolha dos parceiros, tipos de parcerias já realizadas (objetivos, importância e tipo de atores) e fases do desenvolvimento em que os parceiros atuavam.
A parte 3 teve por objetivo classificar o grau de inovação e complexidade do projeto escolhido, para garantir a adequação do projeto aos critérios propostos. Foram solicitados dados do tipo de parceria praticada no projeto (com qual ator, fases do desenvolvimento, quantidade de pessoas colaborando e forma de trabalho da equipe), destacando as motivações, critérios, periodicidade, objetivos das colaborações e, por fim, a "classificação do projeto" segundo critérios de inovação e complexidade.

A quarta parte solicitava ao gerente de cada projeto que avaliasse a presença dos fatores críticos de sucesso por meio de afirmações, em uma escala likert de cinco pontos ("discordo totalmente" até "concordo totalmente"). Além da aplicação do questionário-roteiro, as informações foram posteriormente verificadas por meio de análise documental. 0 roteiro em si pode ser consultado em Reame Junior (2008). A próxima seção apresenta os resultados do estudo de caso bem como a descrição detalhada do critério utilizado na escolha da empresa.

\section{Resultados}

\subsection{Características gerais da empresa estudada}

A empresa localiza-se no interior do estado de São Paulo. Fundada há mais de 50 anos, sua administração é familiar e seu controle acionário é 
de capital fechado. Em 1975, com a evolução dos negócios, foi inaugurada mais uma planta industrial que abriga, hoje, a fundição, com forno de indução elétrico, a usinagem de metais e um laboratório de controle da qualidade das peças. Em 2002 obteve a certificação ISO 9001, versão 2000. Ela exporta para países da América do Norte, da África, do Oriente Médio, da Oceania, da Europa e da América Latina. Possui cerca de 500 funcionários, alocados em quatro áreas ou funções principais, cujos nomes simplificados são: apoio, engenharia, produção e comercial. Na área da engenharia, o número total de funcionários é 55, assim distribuídos:

- 1 engenheiro de produção que ocupa o cargo de gerente executivo da engenharia;

- 4 gerentes de projetos - desenvolvimento de produtos para cana, plantio de verão e inverno, pecuária, fertilizantes e colheitas;

- 8 projetistas de produtos alocados no setor de engenharia de produto;

- 5 projetistas de processos alocados no setor de engenharia de processos;

- 6 funcionários no setor de desenvolvimento e tecnologia (protótipos e testes);

- 10 funcionários no setor de controle da qualidade; e

- 6 funcionários no setor de ferramentaria.

Os demais funcionários (15) são alocados nos projetos de desenvolvimento de produtos para cana, plantio de verão e inverno, pecuária, fertilizantes e colheitas. A empresa possui ainda um comitê, aqui chamado de Comitê de Desenvolvimento de Produto, que é formado pelo gerente executivo da engenharia, pelos líderes das respectivas gerências de projetos e gerentes funcionais da engenharia de produtos, engenharia de processos, desenvolvimento e tecnologia, além do coordenador do escritório de projetos. 0 comitê tem por objetivo discutir e acrescentar melhorias no processo de desenvolvimento de produtos e assessorar os gerentes de projeto e gerentes funcionais na tomada de decisões durante o PDP. A empresa fabrica e comercializa uma variada família de produtos para a atividade agrícola e pecuária, assim distribuída:

- Distribuidores de fertilizantes;

- Máquinas e implementos para a adubação, plantio e cultivo de culturas agrícolas; e

- Implementos para a linha canavieira e para a pecuária.

\subsection{Critério utilizado para a escolha da empresa estudada}

0 critério para a escolha da empresa estudada está fundamentado no trabalho realizado por Simões
(2007), também publicado em Toledo e Simões (2010). A pesquisadora fez um estudo em várias empresas de pequeno e médio porte do segmento de máquinas agrícolas localizadas em diversas regiões do estado de São Paulo e identificou, por meio de uma análise de clusters, três grupos distintos em termos de evolução do PDP.

As empresas do grupo 1 são as que têm o menor nível de maturidade. Com poucos métodos implantados e utilização basicamente do CAD como instrumento para desenvolvimento de produtos. Algumas nem mesmo chegam a utilizar essa tecnologia. 0 grupo 111 é formado pelas empresas de maior nível de maturidade em PDP. Além do CAD, possuem ações formalizadas para testes (realizam lotes-pilotos), aplicam o conceito de transição de fases, realizam registro de lições aprendidas. Mas são incipientes em outras áreas, como a dos indicadores de desempenho. As empresas do grupo 11 estão em uma fase de transição entre as do grupo 1 e 111. A Tabela 1 descreve os resultados do trabalho de Simões (2007) e Toledo e Simões (2010).

A empresa estudada possui características que permitem classificá-la no grupo 111. A Tabela 2 descreve as características da empresa estudada e compara-as com as do modelo de Simões (2007). É possível perceber que a empresa apresenta a maioria das características das empresas do grupo 111, segundo o perfil identificado pela autora. Trata-se de uma empresa com uma estrutura dedicada ao desenvolvimento de produto e com um processo sistematizado por fases, procedimentos e com um avançado procedimento de gestão de portfólio. Possui equipes de projeto e conta até mesmo com um escritório de projetos. O PDP é avaliado por meio de indicadores de desempenho e possui uma sistemática de reuniões, permitindo a integração das equipes de projeto.

\subsection{A colaboração na empresa estudada}

A empresa reconhece a importância da colaboração em desenvolvimento de produtos e procura incentivá-la. Possui casos de colaboração com diferentes agentes tais como os clientes, fornecedores, universidades, centros de capacitação profissional. Em relação à colaboração com os clientes, os principais objetivos destacados são: a pesquisa e desenvolvimento de produtos, ensaios e testes, a coleta de informações e benchmarking. No caso da colaboração com os fornecedores, os principais objetivos são: pesquisa e desenvolvimento de produtos e a assistência técnica durante o projeto, sendo os ensaios e testes menos frequentes. Já com as universidades, os principais objetivos são: a pesquisa e desenvolvimento de produtos, o treinamento e ensaios e testes. Com os centros de capacitação profissional, o objetivo principal 
Tabela 1. Características das dimensões do PDP por grupo.

\begin{tabular}{|c|c|c|c|c|c|}
\hline & & & \multirow{3}{*}{$\begin{array}{l}\text { Grupo } 1 \\
12,50 \%\end{array}$} & \multirow{3}{*}{$\begin{array}{c}\text { Grupo } 11 \\
30 \%\end{array}$} & \multirow{3}{*}{$\begin{array}{c}\text { Grupo } 111 \\
50 \%\end{array}$} \\
\hline & & & & & \\
\hline \multirow{19}{*}{ 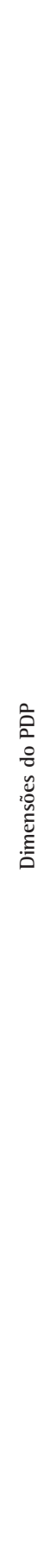 } & \multirow{3}{*}{ 莺 } & $\begin{array}{l}\text { \% de empresas que conhecem o } \\
\text { conceito de gestão de portfólio }\end{array}$ & & & \\
\hline & & $\begin{array}{c}\text { \% de empresas que realizam } \\
\text { pesquisa de mercado de maneira } \\
\text { formal }\end{array}$ & $37,50 \%$ & $60 \%$ & $83,30 \%$ \\
\hline & & $\begin{array}{l}\text { \% de empresas que utilizam } \\
\text { indicadores para avaliar o } \\
\text { desempenho do PDP no todo }\end{array}$ & $0 \%$ & $10 \%$ & $17 \%$ \\
\hline & \multirow{9}{*}{ 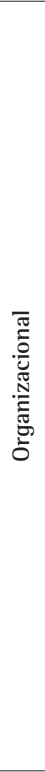 } & $\begin{array}{l}\text { A quem o DP responde } \\
\text { principalmente na empresa }\end{array}$ & $\begin{array}{l}\text { Área própria da empresa } \\
\text { vinculada à presidência/ } \\
\text { diretoria ou setor } \\
\text { vinculado à indústria/ } \\
\text { produção }\end{array}$ & $\begin{array}{c}\text { Área própria da empresa } \\
\text { vinculada à presidência/ } \\
\text { diretoria ou setor } \\
\text { vinculado à indústria/ } \\
\text { produção }\end{array}$ & $\begin{array}{c}\text { Área própria da empresa } \\
\text { vinculada à presidência/ } \\
\text { diretoria ou setor } \\
\text { vinculado à indústria/ } \\
\text { produção }\end{array}$ \\
\hline & & Arranjo organizacional adotado & Matricial & Matricial & Matricial \\
\hline & & $\begin{array}{c}\text { № médio de funcionários que } \\
\text { integram diretamente a área } \\
\text { de DP }\end{array}$ & 3,5 funcionários & 5,7 funcionários & 9,4 funcionários \\
\hline & & $\begin{array}{l}\text { № médio de funcionários com } \\
\text { formação superior na área de DP }\end{array}$ & $\begin{array}{l}0,6 \text { funcionário } \\
(17 \%)\end{array}$ & $\begin{array}{l}1,5 \text { funcionário } \\
(26 \%)\end{array}$ & $\begin{array}{l}\text { 2,9 funcionários } \\
(31 \%)\end{array}$ \\
\hline & & $\begin{array}{l}\text { No médio de equipes que } \\
\text { trabalham simultaneamente na } \\
\text { empresa }\end{array}$ & 7 equipes & 1,7 equipe & 1,5 equipe \\
\hline & & $\begin{array}{l}\text { № médio de funcionários que } \\
\text { participam de cada equipe }\end{array}$ & 3,6 funcionários & 3,8 funcionários & 6,9 funcionários \\
\hline & & $\begin{array}{c}\mathrm{N}^{0} \text { médio de projetos } \\
\text { conduzidos simultaneamente na } \\
\text { empresa }\end{array}$ & 1,5 projeto & 4,2 projetos & 5,3 projetos \\
\hline & & $\begin{array}{l}\text { Principais tipos de parceiros } \\
\text { existentes ao longo do PDP }\end{array}$ & $\begin{array}{c}\text { Fornecedores e clientes } \\
\text { usuários finais }\end{array}$ & $\begin{array}{l}\text { Fornecedores, clientes } \\
\text { usuários finais, } \\
\text { universidades }\end{array}$ & $\begin{array}{c}\text { Fornecedores, clientes } \\
\text { usuários finais, } \\
\text { universidades }\end{array}$ \\
\hline & & $\begin{array}{c}\text { Quantidade de fases do PDP em } \\
\text { que essas parcerias ocorrem }\end{array}$ & 2 fases & 2 fases & 6 fases \\
\hline & \multirow{6}{*}{ 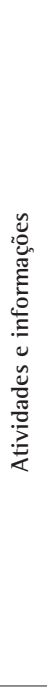 } & $\begin{array}{c}\text { Realização das atividades } \\
\text { da macrofase de pré- } \\
\text { desenvolvimento }\end{array}$ & $\begin{array}{l}49 \% \text { não realiza } \\
46 \% \text { informal } \\
5 \% \text { formal }\end{array}$ & $\begin{array}{l}21 \% \text { não realiza } \\
52 \% \text { informal } \\
28 \% \text { formal }\end{array}$ & $\begin{array}{c}3 \% \text { não realiza } \\
35 \% \text { informal } \\
63 \% \text { formal }\end{array}$ \\
\hline & & $\begin{array}{l}\text { Realização das atividades da } \\
\text { macrofase de desenvolvimento }\end{array}$ & $\begin{array}{l}26 \% \text { não realiza } \\
52 \% \text { informal } \\
23 \% \text { formal }\end{array}$ & $\begin{array}{l}12 \% \text { não realiza } \\
30 \% \text { informal } \\
58 \% \text { formal }\end{array}$ & $\begin{array}{c}6 \% \text { não realiza } \\
14 \% \text { informal } \\
80 \% \text { formal }\end{array}$ \\
\hline & & $\begin{array}{c}\text { Realização das atividades } \\
\text { da macrofase de pós- } \\
\text { desenvolvimento }\end{array}$ & $\begin{array}{c}50 \% \text { não realiza } \\
47 \% \text { informal } \\
3 \% \text { formal }\end{array}$ & $\begin{array}{l}41 \% \text { não realiza } \\
38 \% \text { informal } \\
21 \% \text { formal }\end{array}$ & $\begin{array}{l}25 \% \text { não realiza } \\
19 \% \text { informal } \\
56 \% \text { formal }\end{array}$ \\
\hline & & $\begin{array}{l}\text { \% de empresas que possuem } \\
\text { um procedimento formalizado/ } \\
\text { documentado que define as } \\
\text { atividades do PDP }\end{array}$ & $0 \%$ & $5 \%$ & $58 \%$ \\
\hline & & $\begin{array}{l}\text { \% de empresas que realizam } \\
\text { reuniões de avaliação das } \\
\text { atividades realizadas durante } \\
\text { o PDP }\end{array}$ & $\begin{array}{l}75 \% \text { informal } \\
15 \% \text { não realizam }\end{array}$ & $\begin{array}{l}80 \% \text { informal } \\
20 \% \text { não realizam }\end{array}$ & $\begin{array}{l}50 \% \text { informal } \\
50 \% \text { formal }\end{array}$ \\
\hline & & $\begin{array}{l}\text { \% de empresas que possuem } \\
\text { algum mecanismo formal para } \\
\text { registrar experiências passadas/ } \\
\text { lições aprendidas dos projetos } \\
\text { de DP realizados }\end{array}$ & $0 \%$ & $20 \%$ & $42 \%$ \\
\hline & 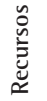 & $\begin{array}{c}\text { Principais ferramentas/métodos } \\
\text { de apoio ao PDP utilizados pelas } \\
\text { empresas }\end{array}$ & CAD & CAD & CAD e Benchmarking \\
\hline
\end{tabular}

é o treinamento. Há experiências mais pontuais com outros agentes, como empresas de consultorias. Nesses casos, considerados de baixa importância, o objeto da colaboração foi a coleta de informações, benchmarking e (em um caso) serviços de detalhamento de engenharia. As motivações apontadas pela empresa para a realização dessas parcerias são:

- Habilidade e conhecimento do cliente: Nesse setor de atuação, há clientes que possuem habilidades e conhecimentos técnicos avançados. Por isso é 
Tabela 2. Comparação do nível de maturidade da empresa estudada segundo o levantamento de Simões (2007).

\begin{tabular}{|c|c|c|}
\hline Características & $\begin{array}{l}\text { Situação das empresas do Grupo } 111 \text { (maior } \\
\text { nível de maturidade) segundo Simões } \\
\text { (2007) }\end{array}$ & Situação da Empresa Estudada \\
\hline $\begin{array}{l}\% \text { de empresas que conhecem o conceito de } \\
\text { gestão de portfólio }\end{array}$ & $50 \%$ & $\begin{array}{l}\text { A empresa não apenas conhece, mas utiliza e } \\
\text { possui a Gestão de Portfólio formalizada no } \\
\text { Sistema Geral da Qualidade (SGQ). } \\
\text { Utiliza critérios. }\end{array}$ \\
\hline $\begin{array}{l}\% \text { de empresas que realizam, de maneira } \\
\text { formal, pesquisa de mercado }\end{array}$ & $83,30 \%$ & $\begin{array}{l}\text { Realiza pesquisa de mercado por meio de sua } \\
\text { rede de vendedores e assistência técnica. } \\
\text { Está formalizado no seu SGQ. }\end{array}$ \\
\hline $\begin{array}{l}\text { \% de empresas que utilizam indicadores para } \\
\text { avaliar o desempenho do PDP no todo }\end{array}$ & $17 \%$ & $\begin{array}{l}\text { Programa de avaliação desempenho do PDP: } \\
\text { Tempo decorrido } \times \text { \% de tarefas realizadas, } \\
\text { Indicadores de custo e qualidade }\end{array}$ \\
\hline $\begin{array}{c}\text { Principais tipos de parceiros existentes ao } \\
\text { longo do PDP }\end{array}$ & $\begin{array}{c}\text { Fornecedores, clientes usuários finais, } \\
\text { universidades }\end{array}$ & $\begin{array}{l}\text { Fornecedores, clientes, empresas de } \\
\text { consultoria, universidades, centros de } \\
\text { formação profissional }\end{array}$ \\
\hline $\begin{array}{c}\text { \% de empresas que possuem algum } \\
\text { mecanismo formal para registrar experiências } \\
\text { passadas/ lições aprendidas dos projetos de } \\
\text { DP realizados }\end{array}$ & $42 \%$ & $\begin{array}{l}\text { Não há um mecanismo formal para registrar } \\
\text { as experiências passadas e lições aprendidas }\end{array}$ \\
\hline $\begin{array}{l}\text { Principais ferramentas /métodos de apoio ao } \\
\text { PDP utilizados pelas empresas }\end{array}$ & CAD e Benchmarking & $\begin{array}{c}\text { CAD 3D } \\
\text { Ferramentas de análise estrutural (CAE) } \\
\text { Instrumentação dinâmica na área de } \\
\text { Engenharia Avançada / Testes }\end{array}$ \\
\hline $\begin{array}{l}\text { Realização das atividades da macrofase de } \\
\text { pré-desenvolvimento }\end{array}$ & $\begin{array}{c}3 \% \text { não realiza } \\
35 \% \text { informal } \\
63 \% \text { formal }\end{array}$ & Formalizado \\
\hline $\begin{array}{l}\text { Realização das atividades da macrofase de } \\
\text { desenvolvimento }\end{array}$ & $\begin{array}{c}6 \% \text { não realiza } \\
14 \% \text { informal } \\
80 \% \text { formal }\end{array}$ & Formalizado \\
\hline $\begin{array}{l}\text { Realização das atividades da macrofase de } \\
\text { pós-desenvolvimento }\end{array}$ & $\begin{array}{l}25 \% \text { não realiza } \\
19 \% \text { informal } \\
56 \% \text { formal }\end{array}$ & Não realiza \\
\hline $\begin{array}{l}\text { A quem o DP responde na empresa } \\
\text { principalmente }\end{array}$ & $\begin{array}{l}\text { Área própria da empresa vinculada à } \\
\text { Presidência / diretoria ou setor vinculado à } \\
\text { Indústria / produção }\end{array}$ & $\begin{array}{l}\text { Área própria da empresa vinculada à } \\
\text { Presidência / diretoria ou setor vinculado à } \\
\text { Indústria / produção }\end{array}$ \\
\hline Arranjo organizacional adotado & Matricial & Matricial \\
\hline $\begin{array}{l}\text { № médio de funcionários que fazem parte } \\
\text { diretamente da área de DP }\end{array}$ & 9,4 funcionários & 8 funcionários \\
\hline $\begin{array}{l}\text { № médio de projetos conduzidos } \\
\text { simultaneamente na empresa }\end{array}$ & 5,3 projetos & 11 projetos nos últimos 5 anos \\
\hline Exportação & $83 \%$ & Exporta para vários países \\
\hline Certificação & $25 \%$ & Certificada 1S0 9001 \\
\hline $\begin{array}{c}\% \text { de empresas que possuem um } \\
\text { procedimento formalizado/documentado que } \\
\text { define as atividades do PDP }\end{array}$ & $58 \%$ & $\begin{array}{l}\text { PDP formalizado, desde a escolha dos } \\
\text { projetos até o lançamento do produto }\end{array}$ \\
\hline $\begin{array}{c}\text { \% de empresas que realizam reuniões de } \\
\text { avaliação das atividades realizadas durante } \\
\text { o PDP }\end{array}$ & $\begin{array}{l}50 \% \text { informal } \\
50 \% \text { formal }\end{array}$ & $\begin{array}{l}\text { Formalizado em documento próprio da } \\
\text { engenharia }\end{array}$ \\
\hline $\begin{array}{l}\text { Quantidade de fases do PDP em que estas } \\
\text { parcerias ocorrem }\end{array}$ & 6 fases & 5 fases \\
\hline $\begin{array}{l}\text { № médio de funcionários que participam de } \\
\text { cada equipe }\end{array}$ & 6,9 funcionários & Dado indisponível \\
\hline $\begin{array}{l}\text { № médio de funcionários com formação } \\
\text { superior na área de DP }\end{array}$ & $\begin{array}{l}2,9 \text { funcionários } \\
(31 \%)\end{array}$ & Dado indisponível \\
\hline $\begin{array}{l}\text { № médio de equipes que trabalham } \\
\text { simultaneamente na empresa }\end{array}$ & 1,5 equipes & Dado indisponível \\
\hline Escritório de Projetos & Dado indisponível & $\begin{array}{l}\text { Conceito introduzido na empresa em } 2005 \text {, } \\
\text { Há um coordenador com dedicação exclusiva }\end{array}$ \\
\hline
\end{tabular}

comum o desenvolvimento colaborativo com eles. Em alguns casos, apoiam o desenvolvimento, sugerindo alterações em máquinas ou mesmo assumindo riscos, como no caso da compra de protótipos, ou permitindo que as máquinas sejam testadas em sua área produtiva; 
- Acesso a testes dos produtos: A colaboração com os clientes, produtores rurais, é importante também para a empresa ter acesso a testes mais realistas dos equipamentos;

- Conhecimentos complementares: Algumas tecnologias que não fazem parte da competência essencial da empresa. Por exemplo, pode-se citar a parte hidráulica e de transmissão das máquinas, onde a empresa desenvolve o conceito e faz o dimensionamento do sistema em conjunto com o fornecedor; e

- Falta de recursos humanos internos especializados: Há momentos de sobrecarga de trabalho de desenvolvimento que são solucionados com a subcontratação de serviços especializados de engenharia, proporcionando intercâmbio de informações e competências.

\subsection{Projeto colaborativo com o cliente}

0 projeto realizado entre a empresa e o cliente foi considerado do tipo nova tecnologia para o mercado. 0 principal diferencial em relação aos produtos similares foi uma inovação técnica que permitia versatilidade maior de acessórios e implementos, tornando-o mais flexível e permitindo maior aproveitamento do equipamento na fazenda. 0 resultado são economias para o produtor rural. Os objetivos da colaboração foram: a coleta de informações; as pesquisas e o desenvolvimento; e os ensaios e testes.

Os principais FCS observados foram: objetivos do projeto claramente definidos; planos do projeto foram acordados mutuamente; recursos foram adequados; houve monitoramento regular do projeto; a comunicação entre os participantes do projeto foi feita de forma eficaz; houve confiança mútua e comprometimento entre os parceiros; houve continuidade das pessoas e boas relações pessoais entre os parceiros; o gerente de projetos tinha conhecimentos técnicos no tema do projeto; experiência multifuncional e em gerenciamento de projeto; era um bom negociador; houve respeito das diferenças culturais entre os parceiros; os profissionais do parceiro possuiam experiência no tema do projeto; o parceiro conhecia e respeitava os objetivos complementares da outra parte, além dos objetivos comuns, o parceiro (cliente) não fazia uso de agendas ocultas, isto é, objetivos não revelados durante o projeto; houve equilíbrio nos benefícios, na contribuição e igualdade de poder entre os parceiros do projeto. 0 projeto contribuiu para as necessidades do mercado; houve estabilidade corporativa durante o projeto.

Os FCS não observados durante o projeto foram: as etapas parciais (milestones) não foram definidas no início do projeto; faltava ao gerente de projeto experiência em colaboração; o parceiro não havia trabalhado antes com a empresa em projetos colaborativos de desenvolvimento de produtos; em nenhum momento do projeto, os parceiros preocuparam-se em aplicar os instrumentos para visualizar, gerenciar e minimizar os riscos.

Este projeto apresentou os seguintes benefícios para a empresa estudada: ganhos no conhecimento em relação à parte agrícola; um produto de sucesso; e o desenvolvimento de uma inovação tecnológica que está sendo explorada em outros produtos. 0 cliente beneficiou-se da melhoria de produtividade e acesso ao equipamento. As dificuldades enfrentadas para gerenciá-lo foram as pressões de prazo e o planejamento mais informal.

\subsection{Projeto colaborativo com o fornecedor}

0 projeto com o fornecedor foi o de uma colheitadeira para milho e outros cereais. Pode ser considerado como uma nova tecnologia para a empresa, mas não para o mercado, pois o conceito do produto já estava estabelecido. Havia, porém, um diferencial no produto, que era o nicho de mercado e sua versatilidade, pois, além da colheita do milho, também poderia ser utilizado para a colheita da soja e do trigo.

Os objetivos da colaboração foram: a pesquisa e o desenvolvimento, a assistência técnica durante o projeto, o treinamento, os ensaios e testes e a coleta de informações.

Como resultado final, tem-se que os principais FCS observados foram: os objetivos do projeto foram definidos claramente; os planos foram acordados mutuamente; houve monitoramento regular do progresso; a comunicação entre os participantes foi feita de forma eficaz; houve confiança mútua e comprometimento entre os parceiros; houve continuidade das pessoas e bom relacionamento entre os parceiros; a direção da empresa estudada incentivou durante todas as etapas; houve um champion (participante que exerce o papel de motivador do grupo) de colaboração. 0 gerente do projeto foi um bom negociador, possuía experiência multifuncional; o parceiro possuía experiência no tema; conhecia e respeitava os objetivos complementares, além dos objetivos comuns; o fornecedor-parceiro não fazia uso de agendas ocultas. Neste projeto também houve equilíbrio de contribuição e benefícios, além de igualdade de poder entre os parceiros. 0 produto veio ao encontro das necessidades do mercado, mas teve venda menor que o esperado pois a empresa 
passou por período de reestruturação em virtude da situação econômica vivida pelo setor no lançamento.

Os FCS não realizados durante o projeto foram: as etapas parciais não foram definidas desde o início; o gerente de projetos não tinha experiência em gerenciamento de projetos e em colaboração; não tinha conhecimento técnico no tema; o fornecedor não havia trabalhado anteriormente em projetos colaborativos com a empresa e, sim, apenas fornecia materiais; os parceiros não fizeram uso de procedimentos formais para identificação, administração ou minimização de riscos futuros.

Os benefícios advindos dessa colaboração para a empresa foram: produto com grande potencial e previsões de vendas em nível mundial; o produto contribuiu muito para diminuir a sazonalidade; agregação de conhecimentos em relação às inovações tecnológicas e ao plantio das culturas do milho, da soja e do trigo. Para o fornecedor, os benefícios foram: o aumento no faturamento; tornou-se um canal de distribuição do produto.

A dificuldade encontrada pela empresa estudada nessa colaboração deu-se na troca de informações. Houveram alterações em desenhos e outros documentos, por parte do fornecedor-parceiro, que não as informava ao projetista da empresa. Apesar dessas divergências, solucionadas rapidamente, o resultado final do projeto trouxe satisfação mútua para os parceiros.

\section{Análise comparativa dos projetos}

$\mathrm{Na}$ análise, é verificada uma grande similaridade entre os FCS presentes nos dois projetos. Poucas são as divergências. Porém, quando ocorreram, foi possível notar prejuízos aos projetos, pois apareceram como barreiras que tiveram que ser superadas no decorrer da colaboração. É o caso de recursos adequados, "respeito às diferenças culturais" e "estabilidade corporativa", no projeto com o fornecedor. No caso do projeto com o cliente, há a ausência do "champion de colaboração".

Os fatores: "equilíbrio de benefícios (benefícios mútuos)", "igualdade de poder", "equilíbrio de contribuição", "alinhamento com as necessidades do mercado", "estabilidade corporativa", "confiança”, "comprometimento", "aprendizado documentado", "continuidade de equipes", "bom relacionamento" foram os mais presentes em ambos os projetos e demonstraram ser realmente fundamentais para o sucesso da colaboração. Eles foram responsáveis por auxiliar a suplantar os obstáculos gerados pela ausência dos FCS mencionados.

Outro aspecto que chama a atenção relaciona-se à avaliação dos parceiros. Nos dois projetos, a ausência de experiência dos parceiros em colaborações em outras empresas não influenciou o resultado.

Em ambos, também foi fundamental o FCS "respeito aos objetivos complementares". Esse parece ser o FCS realmente crítico. Sugerindo que os demais possam ser secundários e, portanto, menos importantes.

0 FCS adicionado "gerenciamento de riscos" não foi verificado em nenhum projeto e foi considerado

Quadro 2. Comparação dos FCS do modelo teórico e os FCS dos projetos colaborativos (elaborado pelo autor).

\begin{tabular}{|c|c|c|}
\hline \multirow[b]{2}{*}{ Sintese de fatores criticos (1) } & \multicolumn{2}{|c|}{$\begin{array}{l}\text { Projetos colaborativos da } \\
\text { empresa estudada }\end{array}$} \\
\hline & $\begin{array}{c}\text { com o } \\
\text { cliente } \\
(2)\end{array}$ & $\begin{array}{c}\text { com o } \\
\text { fornecedor } \\
\text { (3) }\end{array}$ \\
\hline \multicolumn{3}{|l|}{$\begin{array}{l}\text { Objetivos e responsabilidades } \\
\text { definidos }\end{array}$} \\
\hline \multicolumn{3}{|l|}{ Objetivos realistas } \\
\hline \multicolumn{3}{|l|}{$\begin{array}{l}\text { Planos do projeto acordados } \\
\text { mutuamente }\end{array}$} \\
\hline \multicolumn{3}{|l|}{ Recursos adequados } \\
\hline \multicolumn{3}{|l|}{$\begin{array}{l}\text { Etapas parciais definidas } \\
\text { (milestones) }\end{array}$} \\
\hline \multicolumn{3}{|l|}{ Monitoramento } \\
\hline \multicolumn{3}{|l|}{ Comunicação eficiente } \\
\hline \multicolumn{3}{|l|}{ Confiança } \\
\hline \multicolumn{3}{|l|}{ Comprometimento } \\
\hline \multicolumn{3}{|l|}{ Aprendizado documentado } \\
\hline \multicolumn{3}{|l|}{ Continuidade das equipes } \\
\hline \multicolumn{3}{|l|}{ Bom relacionamento } \\
\hline \multicolumn{3}{|l|}{ Champion da colaboração } \\
\hline \multicolumn{3}{|l|}{$\begin{array}{l}\text { Experiência como gerente de } \\
\text { projeto }\end{array}$} \\
\hline \multicolumn{3}{|l|}{ Gerente negociador } \\
\hline \multicolumn{3}{|l|}{ Experiência em colaboração } \\
\hline \multicolumn{3}{|l|}{ Experiência multifuncional } \\
\hline \multicolumn{3}{|l|}{ Capacitação técnica } \\
\hline \multicolumn{3}{|l|}{$\begin{array}{l}\text { Respeito às diferenças culturais } \\
\text { entre os parceiros }\end{array}$} \\
\hline \multicolumn{3}{|l|}{$\begin{array}{l}\text { Experiência em colaboração com } \\
\text { outras empresas }\end{array}$} \\
\hline \multicolumn{3}{|l|}{$\begin{array}{l}\text { Experiências anteriores em projetos } \\
\text { com a empresa }\end{array}$} \\
\hline \multicolumn{3}{|l|}{$\begin{array}{l}\text { Profissionais do parceiro com } \\
\text { experiência no tema }\end{array}$} \\
\hline \multicolumn{3}{|l|}{$\begin{array}{l}\text { Respeito aos objetivos } \\
\text { complementares }\end{array}$} \\
\hline \multicolumn{3}{|l|}{$\begin{array}{l}\text { Sem agendas ocultas (objetivos não } \\
\text { revelados) }\end{array}$} \\
\hline \multicolumn{3}{|l|}{ Conhecimentos especializados } \\
\hline \multicolumn{3}{|l|}{ Habilidades complementares } \\
\hline \multicolumn{3}{|l|}{$\begin{array}{l}\text { Equilíbrio de benefícios (benefícios } \\
\text { mútuos) }\end{array}$} \\
\hline \multicolumn{3}{|l|}{ lgualdade de poder } \\
\hline \multicolumn{3}{|l|}{ Equilíbrio de contribuição } \\
\hline $\begin{array}{l}\text { Alinhamento com as necessidades } \\
\text { do mercado }\end{array}$ & & \\
\hline \begin{tabular}{|l|} 
Estabilidade corporativa \\
\end{tabular} & & \\
\hline $\begin{array}{l}\text { Análise e acompanhamento de } \\
\text { riscos }\end{array}$ & & \\
\hline
\end{tabular}


como um fator não crítico pelos respondentes. Porém, se considerarmos os problemas que surgiram com a falta de recursos e alterações nos requisitos no projeto com o fornecedor, resta a dúvida se realmente a presença desses fatores não poderia ter evitado esses problemas.

Uma hipótese que o trabalho sugere é que o efeito da gestão de riscos teria sido minimizado pela presença forte de fatores como "confiança" e "bom relacionamento".

0 Quadro 2 faz um alinhamento entre os FCS pesquisados na revisão bibliográfica, comparando-os quanto à observação nos projetos colaborativos analisados. A coluna (1) contém os FCS da revisão bibliográfica. Na coluna (2), identificam-se os FCS presentes no projeto em colaboração com o cliente, por meio dos campos preenchidos em cinza. A coluna (3) contém os FCS presentes no relacionamento com o fornecedor. Uma análise permite demonstrar a situação de semelhança entre os dois projetos estudados.

\section{Conclusões gerais}

0 trabalho apresentou os resultados da avaliação de fatores críticos para o sucesso de dois projetos colaborativos de desenvolvimento de máquinas agrícolas que agregaram significativa inovação. Um deles foi desenvolvido em parceria com o cliente, o outro, em parceria com um fornecedor. Os FCS presentes nos dois projetos foram comparados com a literatura e entre si.

A primeira conclusão importante é que os fatores propostos na literatura foram em grande parte reforçados por esta pesquisa e considerados pelos gerentes de projetos das empresas como fundamentais para o sucesso.

A segunda conclusão é que o trabalho aponta oportunidades para a simplificação da lista de FCS identificada. A evidência maior está nos fatores: "experiência do parceiro em colaboração com outras empresas", "experiências anteriores em projetos com a empresa", "conhecimentos especializados" e "habilidades complementares". Tais fatores, ditos críticos, estavam ausentes e não foram considerados geradores de obstáculos ao andamento do projeto. Isso implica que talvez não sejam fatores "críticos" e, portanto, poderiam ser simplificados em levantamentos na área.

Uma terceira conclusão da pesquisa emerge da similaridade entre os FCS observados nos dois projetos. A opção pela estratificação quanto ao tipo de colaboração foi motivada pela hipótese de que poderia haver diferenças relacionadas a esse aspecto, sugeridas na literatura. A comparação desses dois projetos, porém, não indicou diferenças significativas quanto ao tipo de parceiro. Mostra, sim, que os fatores “confiança”, "comprometimento", “aprendizado documentado", "continuidade de equipes", "bom relacionamento" foram fundamentais, reforçando a teoria da área.

Essa conclusão, logicamente, precisa ser tomada com cuidado. 0 resultado é pouco expressivo, pois trata-se de um estudo de caso. A questão, cuja resposta plena não era propósito do estudo, deve ser mais bem compreendida. 0 dado em si, porém, pode ser tomado como um indício que motiva novas pesquisas sobre este tema específico.

Outra conclusão do estudo é a identificação da hipótese de existência de fatores erroneamente citados como críticos na literatura. Um exemplo é o fator "conhecimento técnico" do gerente de projeto. Nos dois projetos, a maior competência técnica estava presente na equipe, mas não na figura do gerente de projeto. Elas eram de domínio de profissionais das organizações parceiras, que participavam da equipe. Porém, isso não significou empecilho ou obstáculo para a condução do projeto. As competências do gerente de projeto em negociação e em visão multifuncional foram suficientes para criar uma visão comum, no caso, um bom foco para o mercado e objetivos.

A pesquisa indica a hipótese de que os fatores críticos "domínio técnico do gerente de projeto" e "profissionais do parceiro com experiência no tema" poderiam ser sintetizados em um único, sobre a equipe de projeto, denominado, por exemplo, "equipe com todas as competências técnicas necessárias". Isso porque, conforme demonstrado nos casos, mais importante é que exista a competência na equipe de projeto, independentemente de residir no gerente de projeto ou no parceiro. Outros fatores como confiança, perfil de negociação do gerente e experiência multifuncional do gerente permitiriam que esse conhecimento da equipe fosse efetivamente transformado em boas soluções técnicas, garantindo o sucesso do projeto.

Este trabalho é um primeiro esforço para a identificação e elaboração de uma lista de FCS que possa ser validada para a IMA brasileira. A principal contribuição é demonstrar uma sistematização da literatura da área, identificando fatores críticos presentes na literatura. Outra contribuição é uma primeira verificação desses fatores em casos da indústria de máquinas agrícolas, identificando aspectos que podem orientar outros pesquisadores na utilização desses fatores em estudos mais amplos, do tipo levantamento, específicos sobre essa indústria.

0 trabalho serve também como um alerta sobre a importância do tema. Desenvolver técnicas, métodos e modelos gerenciais para a IMA é fundamental para a competitividade do país. Um dos aspectos é a colaboração. A principal sugestão para trabalhos futuros é a realização de levantamentos sobre a 
situação da colaboração e dos fatores críticos de sucesso nesse tipo de projeto e indústria, explorando outros atores como institutos de pesquisa e um conjunto maior de empresas.

\section{Referências}

ALBERTIN, E. V.; AMARAL, D. C. Contexto da parceria como qualificador da gestão de projetos universidade-empresa. Produção, v. 20, n. 2, 2010. Disponível em: <http:// www.scielo.br/scielo.php?script=sci_arttext\&pid= S0103-65132010000200008\&lng $=$ pt\&nrm $=$ iso $>$. Acesso em: 29 ago. 2011. http://dx.doi.org/10.1590/ S0103-65132010005000033

ASSOCIAÇÃO BRASILEIRA DA INDÚSTRIA DE MÁQUINAS E EQUIPAMENTOS - ABIMAQ. Máquinas agrícolas contribuem para resultado positivo. Informaq Jornal, n. 102, 2007. Disponível em: <http://www.abimaq.com. br>. Acesso em: 28 jun. 2007.

ASSOCIAÇÃO NACIONAL DOS FABRICANTES DE VEÍCULOS AUTOMOTORES - ANFAVEA. Anuário Estatístico da Indústria Automobilística Brasileira. São Paulo: ANFAVEA, 2006. Disponível em: <http://www.anfavea. com.br/anuário2007/cap01.2007pdf.>. Acesso em: 16 jun. 2007.

AVELlAR, A. P. Setor: Bens de Capital. FINEP, 2008. Relatório Setorial Final. Disponível em: $\quad<$ http://www.finep.gov.br/PortalDPP/ relatorio-setorial-final/relatorio-setorial-final_impressao. asp?lst-setor=5,2008>. Acesso em: 21 mar. 2008.

BADIN, N. T. Modelo de referência para o processo de desenvolvimento de produtos integrando fornecedores e baseado nos conceitos de engenharia simultânea, custeio-alvo e empresa virtual. 2005. 223 f. Tese (Doutoradoem Engenharia de Produção)-Universidade Federal de Santa Catarina, Florianópolis, 2005.

BARBALHO, S. C. M. et al. Rompendo obstáculos para a implantação de escritório de projetos em empresa de base tecnológica. Gestão \& Produção, v. 16, n. 3, 2009. Disponivel em: <http://www.scielo.br/scielo. php?script=sci_arttext\&pid=S0104-530X200900030001 0\&lng=pt\&nrm=iso $>$. Acesso em: 29 ago. 2011. http:// dx.doi.org/10.1590/S0104-530X2009000300010

BARCZAK, G.; WILWEMON, D. Factors influencing product development teams satisfaction. European Journal of Innovation Management, v. 4, n. 1, p. 32, 36, 2001.

BARNES, T. A.; PASHBY, I. R.; GIBBONS, A. M. Effective University - Industry Interaction: A multi-case evaluation of collaborative R\&D projects. European Management Journal, v. 20, n. 3, p. 272-285, 2002. http://dx.doi. org/10.1016/S0263-2373(02)00044-0

BARNES, T. A.; PASHBY, I. R.; GIBBONS, A. M. Managing collaborative R\&D projects development of a practical management tool. International Journal of Project Management, v. 24, p. 395-404, 2006. http://dx.doi. org/10.1016/j.jproman.2006.03.003

BLINDENBACH-DRIESSEN, F.; VAN DEN ENDE, J. Innovation Management Practices Compared: The Example of Project-Based Firms. Journal of Product Innovation Management, v. 27, n. 5, p. 705-724, 2010. http:// dx.doi.org/10.1111/j.1540-5885.2010.00746.x

CAPELL1, N. Agricultura brasileira e o fenômeno da globalização. 2008. Disponível em: <http://gpsglobal. com.br>. Acesso em: 19 mar. 2008.

CERRI, D. G. P. Agricultura de precisão em cana de açúcar. instrumentação de uma colhedora, mapeamento da produtividade e de atributos do solo. 2005. $156 \mathrm{f}$.
Tese (Doutorado em Engenharia Agrícola)-Universidade Estadual de Campinas, Campinas, 2005.

CHESBROUGH, H. W. Open Innovation: The New Imperative for Creating and Profiting from Technology. Boston: Harvard Business School Press, 2003.

CHESBROUGH, H. W.; SCHWARTS, K. Innovating business models with co-development partnerships.Research Technology Management, v. 50, n. 1, 2007.

CLARO, D. P.; OLIVEIRA CLARO, P. B. Gerenciando relacionamentos colaborativos com fornecedores. RAE-Revista de Administração de Empresas, v. 44, n. 4, p. 69,2004

CLARK, R. L.; McGUCKIN, R. L. Variable rate application equipment for precision farming. Athens, 1996. Disponivel em <http://www.engr.uga.edu/research/ groups/precisionfarming/clarck_urt.html\# over>. Acesso em: 22 jun. 2007.

DODGSON, M. The future for technological collaboration. Futures, p. 459-470, 1992. http://dx.doi. org/10.1016/0016-3287(92)90016-9

DOMAZET, D. et al. An Infrastructure for Inter-Organizational Collaborative Product Development. In: INTERNATIONAL CONFERENCE ON SYSTEM SCIENCES, 33., 2000, Hawaii. Proceedings... IEEE, 2000. http://dx.doi.org/10.1109/ HICSS.2000.926876

DONG, T. et al. A collaborative approach to assembly sequence planning. Advanced Engineering Informatics, v. 19, p. $155-168,2005$. http://dx.doi.org/10.1016/j. aei.2005.05.008

GADANHA JUNIOR, C. D. et al. Máquinas e implementos agrícolas no Brasil. São Paulo: IPT, 1991.

GRIFFIN, A. The effect of project and process characteristics on product development cycle time. Journal of Marketing Research, v. 34, n. 1, p. 24-35, 1997. http://dx.doi. $\operatorname{org} / 10.2307 / 3152062$

GRUDIN, J. Computer-supported cooperative work: its history and participation. IEEE Computer, v. 27, n. 5, p. 19-26, 1994. http://dx.doi.org/10.1109/2.291294

HAGEDOORN, J. Understanding the rationale of strategic technology partnering: inter-organizational modes of co-operation and sectorial differences. Strategic Management Journal, n. 14, p. 371-386, 1993. http:// dx.doi.org/10.1002/smj.4250140505

HAMEL, G.; DOZ, Y.; PRAHALAD, C. K. Collaborative with your competitors and win.Harvard Business Review, v. 67, n. 1, p. 133-139, 1989.

HEINZ, U. et al. Leadership and cooperation as success factors in innovative R\&D projects on electronics platforms. Team Performance Management, v. 12, n. 3-4, p. 66-76, 2006. http://dx.doi.org/10.1108/13527590610674077

HUSTON, L.; SAKKAB, N. Connect and Develop: inside Procter \& Gamble's new model for innovation. Harvard Business Review, 2006.

HYVÄRl, 1. Success of projects in different organizational conditions. Project Management Journal, p.33-41, 2006.

KAYIS, B. IRMAS - development of a risk management tool for collaborative multi-site, multi-partner new product development projects. Journal of Manufacturing Techonology Management, v. 18, n. 4, p. 387-414, 2007. http://dx.doi.org/10.1108/17410380710743770

KLEINSMANN, M.; VALKENBURG, R. Learning from collaborative new product development projects. Journal of Workplace Learning, v. 17, n. 3, p. 146-156, 2005. http://dx.doi.org/10.1108/13665620510588671

KNUDSEN, M. P. The relative importance of interfirm relationships and knowledge transfer for new product 
development success. Journal Product Innovation Management, v. 24, p. 117-138, 2007. http://dx.doi. $\operatorname{org} / 10.1111 / \mathrm{j} .1540-5885.2007 .00238 . x$

LAM, P. K.; CHIN, K. S. Project factors influencing conflict intensity and handling styles in collaborative NPD. Creativity and Innovation Management, v. 13, n. 1, 2004. http://dx.doi.org/10.1111/j.1467-8691.2004.00293.x

LAM, P. K.; CHIN, K. S. PUN, K. F. Managing conflict in collaborative new product development: a supplier perspective. International Journal of Quality \& Realibility Management, v. 24, n. 9, p. 891-907, 2007. http:// dx.doi.org/10.1108/02656710710826171

MARTINEZ, J. Precisão via satélite: Editorial. Revista O Sulco, ano 112 , n. 27, p. 3, 2007. Edição brasileira da revista agrícola mundial publicada em 12 línguas pela Deere \& Company e suas subsidiárias.

MARTINI, E. et al. Tecnologia Aplicada. Revista Cultivar Máquinas, ano 4, n. 49, p. 22-26, 2006.

MIALHE, L. G. Manual de mecanização agrícola. São Paulo: Agronômica Ceres, 1974.

NICOLETTA, G. Alta nos grãos impulsiona vendas de máquinas agrícolas. Disponível em: <http://www.estadao.com. br/economia/not_eco166013,0.htm>. Acessoem: 03 maio 2008.

PARUNG, J.; BITITCl, U. S. A conceptual metric for managing collaborative networks. Journal of Modelling Management, v. 1, n. 2, p. 116-136, 2006. http://dx.doi. org/10.1108/17465660610703468

PASQUAL, C. A.; PEDROSO, E. A. Características do negócio de máquinas agrícolas. RAE - eletrônica, v. 6, n. 1, art 3, 2007. Disponivel em: <http:// www.rae.com.br/ eletrônica>. Acesso em: 26 jun. 2007.

REAME JUNIOR, E. Fatores críticos de sucesso na gestão de projetos colaborativos de desenvolvimento de máquinas agrícolas: um estudo de caso. 2008. 153 f. Dissertação (Mestrado em Engenharia de Produção)-Universidade de São Paulo, São Carlos, 2008.

ROCKART, J. F. Chief executives define their own data needs. Harvard Business Review, 1979.

ROMANO, L. N. Modelo de referência para o processo de desenvolvimento de máquinas agrícolas. 2003. $321 \mathrm{f}$. Tese (DoutoradoemEngenhariaMecânica) - Universidade Federal de Santa Catarina, Florianópolis, 2003.

SAVANACHI, E. Os motores do agronegócio. Revista Panorama Rural, ano 9, n. 100, p. 32-37, 2007.

SCHNEIDER, A. Project management in international teams: instruments for improving cooperation. International
Journal of Project Management, v. 13, n. 4, p. 247-251, 1995. http://dx.doi.org/10.1016/02637863(95)00022-1

SIMÕES, J. M. S. Perfil de maturidade do processo de desenvolvimento de produtos em empresas de pequeno e médio porte do setor de máquinas e implementos agrícolas. 2007. 147 f. Dissertação (Mestrado em Engenharia de Produção)-Universidade Federal de São Carlos, São Carlos,2007.

SIVADAS, E.; DWYER, F. R. An examination of organizational factors influencing new product success in internal and Alliance-Based Processes. Journal of Marketing, v. 64 , n. 1, p. 31-49, 2000. http://dx.doi.org/10.1509/ jmkg.64.1.31.17985

TOLEDO, J. C. et al. Fatores críticos de sucesso no gerenciamento de projetos de desenvolvimento de produto em empresas de base tecnológica de pequeno e médio porte. Gestão \& Produção, v. 15, n. 1, 2008a.Disponível em: <http://www.scielo.br/scielo. php?script=sci_arttext\&pid=S0104-530X200800010001 $1 \& \operatorname{lng}=$ pt\&nrm=iso $>$. Acesso em: 29 ago. 2011. http:// dx.doi.org/10.1590/S0104-530X2008000100011

TOLEDO, J. C. et al. Práticas de gestão no desenvolvimento de produtos em empresas de autopeças. Produção, v. 18, n. 2, 2008 b. Disponível em: <http://www.scielo.br/ scielo.php?script=sci_arttext\&pid=S0103-65132008000 200015\&lng=pt\&nrm=iso>. Acesso em: 29 ago. 2011. http://dx.doi.org/10.1590/S0103-65132008000200015

TOLED0, J. C.; SIMOES, J. M. S. Gestão do desenvolvimento de produto em empresas de pequeno e médio porte do setor de máquinas e implementos agrícolas do Estado de SP. Gestão \& Produção, v. 17, n. 2, 2010. Disponível em: $\quad<$ http://www.scielo.br/scielo.php?script=sci arttext\&pid=S0104-530X2010000200004\&lng =pt \&nrm=iso>. Acesso em: 29 ago. 2011. http://dx.doi. org/10.1590/S0104-530X2010000200004

TORRICO, R. Máquinas voltadas para o futuro. Revista Panorama Rural, ano 9, n. 100, p. 38-39, 2007.

VAN WYK, R.; BOWEN, P.; AKINTOYE, A. Project risk management practice: The case of South African utility company. International Journal of Project Management, v. 26, p. 149-163, 2008. http://dx.doi.org/10.1016/j. ijproman.2007.03.011

VON STAMM. Collaboration with other firms and customers: innovation's secret weapon. Strategyand Leadership, v. 32, n. 3, p. 16-20, 2004.

YIN, R. K. Estudo de caso: planejamento e métodos. 3. ed. Porto Alegre: Bookman, 2005.

\section{Critical success factors in collaborative projects in industry of agricultural machinery}

\section{Abstract}

The collaborative product development is essential for companies to increase the innovation degree of their products. Companies must follow the critical success factors (CSF) in order to achieve the expected results. There is a set of papers that identified critical success factors (CSF) for collaborative projects; however, there is no paper verifying those factors in Brazil, especially in the Agricultural Machinery Industry. This article aims to verify whether the CSFs identified in the literature could be used in this context. A bibliographical review was carried out to identify a CSF list. After that, a single case study was developed, using the project as unit of analysis. Two successful and collaborative projects were evaluated. The results described new CSFs and reinforced others, as factors related to relationship equality and universality.

\section{Keywords}

Collaborative projects. Agricultural machinery. Critical success factors. 